ERRAT UM

\title{
Automatic avoidance of obstacles is a dorsal stream function: evidence from optic ataxia
}

Igor Schindler, Nichola J Rice, Robert D McIntosh, Yves Rossetti, Alain Vighetto \& A David Milner

Nat. Neurosci. 7, 779-784 (2004)

Table 2 on page 781 contained a typographical error, a superfluous letter introduced into one of the numbers, which were otherwise correct. The corrected version appears below.

Table 2 Kinematic parameters of movements in the reach task

$\begin{array}{lccl}\text { Subject } & \text { MT } & \text { PV } & \text { TPV } \\ \text { A.T. } & 830.7 & 1,033.6 & 324.7 \\ \text { I.G. } & 561.4 & 1,598.2 & 171.6 \\ \text { C1 } & 480.3 & 1,757.8 & 189.9 \\ \text { C2 } & 590.4 & 1,671.5 & 220.7 \\ \text { C3 } & 656.2 & 1,458.1 & 207.4 \\ \text { C4 } & 454.4 & 2,008.9 & 156.3 \\ \text { C5 } & 711.1 & 1,295.2 & 209.8 \\ \text { C6 } & 617.3 & 1,226.8 & 260.6 \\ \text { C7 } & 601.3 & 1,365.3 & 251.2 \\ \text { C8 } & 454.0 & 1,959.5 & 142.8 \\ \text { Mean C } & 570.6 & 1,592.9 & 204.8\end{array}$

MT, mean movement time (ms); PV, mean peak velocity in the horizontal $(x-y)$ plane $(\mathrm{mm} / \mathrm{s}) ; \mathrm{TPV}$, time to peak velocity in the $x-y$ plane $(\mathrm{ms})$. The start and end of each movement was defined as a rise or fall below a threshold velocity of $50 \mathrm{~mm} / \mathrm{s}$. Data are given individually for patients A.T. and I.G. and for 8 healthy control subjects (C1-C8). 